\title{
The impact of the COVID-19 outbreak on supportive care for oral mucositis: current concepts and practice
}

\author{
Pierluigi Bonomo ${ }^{1}$ Sharon Elad ${ }^{2} \cdot$ Tomoko Kataoka $^{3} \cdot$ Paolo Bossi ${ }^{4} \cdot$ on behalf of the Mucositis Study Group of \\ MASCC/ISOO
}

Received: 23 September 2020 / Accepted: 16 December 2020 / Published online: 4 January 2021

(C) The Author(s), under exclusive licence to Springer-Verlag GmbH, DE part of Springer Nature 2021

\begin{abstract}
The outbreak of coronavirus disease 2019 (COVID-19) markedly affected the way healthcare professionals approach patients with cancer worldwide, not only in terms of therapeutic decision-making but also in terms of supportive care. With the rapid appearance of signs and symptoms and the need of close re-assessment, standard management of oral mucositis has been challenged by physical distancing and limited resources due to the global crisis. Building on the clinical experience developed during the acute phase by members of the Mucositis Study Group of the Multinational Association of Supportive Care in Cancer/ International Society of Oral Oncology (MASCC/ISOO), the implications of COVID-19 on the prevention, assessment, and treatment of mucositis are critically reported. Inspired by the restructuring of supportive care measures in response to the pandemic, suggestions for new models of approaching acute side effects are also discussed.
\end{abstract}

Keywords Mucositis $\cdot$ Chemotherapy $\cdot$ Radiotherapy $\cdot$ COVID- $19 \cdot$ Telemedicine $\cdot$ Supportive care

Oral mucositis (OM), a complication of cancer therapy, can be viewed as a model for the clinical approach to an acute oral disease during times of a pandemic. During the first few months of the COVID-19 pandemic, while the mortality rate was high, a medical supplies shortage was noted, and health systems were on the margin of a collapse; in many countries, governmental orders approved delivery of emergency medical/dental only. At the same time, cancer therapy continued, and OM needed to be addressed timely. An important

\section{Sharon Elad}

SElad@urmc.rochester.edu

1 Department of Radiation Oncology, Azienda Ospedaliero-Universitaria Careggi, University of Florence, Florence, Italy

2 Division of Oral Medicine, Eastman Institute for Oral Health, University of Rochester Medical Center, University of Rochester, 625 Elmwood Ave., Rochester, NY 14620, USA

3 Multi-institutional Clinical Trials Section, Research Management Division, Clinical Research Support Office, National Cancer Center Hospital, Tokyo, Japan

4 Department of Medical \& Surgical Specialties, Radiological Sciences \& Public Health, ASST Spedali Civili, University of Brescia, Brescia, Italy lesson was learned during this time, which may be helpful during situations in which there is a concern about the spread of infection, and interactions with the patient may be limited.

The Mucositis Study Group (MSG) of MASCC/ISOO collected input from its members and discussed practical suggestions on current supportive care measures for OM, spurred by the COVID-19 crisis. These aspects of supportive care are summarized below and presented relative to the pertinent MASCC/ISOO clinical practical guidelines for the management of OM (Table 1).

\section{Oral assessment and dental clearance before cancer therapy}

Dental clearance before cancer therapy reduces infections and risk of mucositis during treatment. Dentists often perform this treatment using a rotatory high-speed hand-piece that produces a large aerosol. It is necessary to prevent the scatter of saliva and aerosols while choosing more appropriate procedures and instruments, or by applying a new scavenging technology. The CDC published new guidance for the dental setting (https:// www.cdc.gov/coronavirus/2019-ncov/hcp/dental-settings. $\mathrm{html}$ ), requiring adoption of rigorous safety measures for both 
Table 1 MASCC/ISOO mucositis guidelines — possible adjustment to accommodate the special COVID-19 pandemic circumstances

\begin{tabular}{ll}
\hline Guideline category & Adjustment to the COVID-19 pandemic setting \\
\hline 1 Dental clearance prior to the cancer therapy & - Modifications to the delivery of dental care \\
& - Preference of aerosol-free instruments and procedures \\
& - Universal personal protective equipment is upgraded \\
& - Emphasize on education in order to enhance patient self-care and improve basic oral care \\
& - Use of telemedicine to deliver instructions to patients \\
& - Use of electronic patient-reported outcome systems to assess mucositis symptoms \\
& - Intra-oral preventive protocols continued \\
& - Extra-oral application was explored given it is associated with a lower risk for infection transmission \\
\hline
\end{tabular}

patients and healthcare professionals, and the correct use of personal protective equipment (PPE).

\section{Clinical assessment of the oral mucosa during cancer therapy}

Since social distancing is considered an important element in reducing the spread of infection, in-office visits might be limited during pandemia. In this setting, the use of electronic patient-reported outcomes (e-PROs) enables timely interaction with the patient for optimal symptom assessment in a period of reduced patient-physician interaction. It has long been known that self-reporting of quality of life has a prognostic impact on survival in cancer patients $[1,2]$ : the COVID-19 outbreak highlighted the importance of early detection of side effects through active patient selfreporting for best supportive care [3]. In this regard, the implementation of e-PRO may help to early identify mucositis based on its associated symptoms (pain, infection, dysgeusia, dysphagia). The use of mucositis-specific PRO tools (as the Oral Mucositis Daily Questionnaire, OMDQ) [4] or the adoption of specific item library of PROCTCAEe for head and neck cancer patients constitute additional examples of application [5].

If a patient office visit is permitted, an oral examination is not considered high risk for viral contagion relative to other dental procedures, and eye-mouth-face and gown PPE is likely deemed sufficient; however, there is variability between institutes as to how to approach PPE.

Another tool utilized during oral assessment to reduce the spread of infection through the aerosol is a pre-examination anti-microbial rinse. There are limited data on which mouthwash has the optimal anti-SARS-CoV-2 effect. As it seems now, povidone iodine may have some virucidal effect [6-8], while data about chlorhexidine and hydrogen peroxide are conflicting $[6,9]$. As per the current CDC guidance for the dental setting, "there is no published evidence regarding the clinical effectiveness of preprocedural mouth rinses (PPMRs) to reduce SARS-CoV-2 viral load or to prevent transmission. Although COVID-19 was not studied, PPMRs with an antimicrobial product (chlorhexidine gluconate, essential oils, povidone-iodine or cetylpyridinium chloride) may reduce the level of oral microorganisms in aerosols and spatter generated during dental procedures" (https://www.cdc.gov/ coronavirus/2019-ncov/hcp/dental-settings.html). Importantly, the guidance does not convey efficacy in preventing or treating OM.

\section{Basic oral care}

The recently updated MASCC/ISOO guidelines suggested that patient education of basic oral care should be considered a critical factor in ensuring adherence to the guidelines [10]. While access to healthcare may be limited, motivating the patient for self oral hygiene care becomes ever more important.

\section{Specific OM-preventive protocols}

As published by judicious refinements of standard practice guidelines [11-13], management of cancer therapy related acute side effects should be optimized during a pandemic outbreak. This may apply for OM in regard to photobiomodulation (PBM).

Intra-oral photobiomodulation is one of the recommended modes for the prevention of OM [14]. The MASCC/ISOO guideline related to $\mathrm{PBM}$ refers to a specific cancer patient population, specific delivery protocols, and a specific PBM setting. Despite limited evidence, extra-oral PBM was prioritized during the COVID-19 outbreak in order to reduce the risk of droplet contamination [15]. Its theoretical advantage in terms of patient convenience was preliminarly demonstrated for pediatric patients undergoing HCST [16]. 


\section{Telemedicine: bridge to remote communication}

Telemedicine usually allows a live interaction with the patient, including video image, which dramatically improves the communication with the patient, and hence the patient's understanding of the treatment recomendations. Head and neck oncology, otolaryngology, oral medicine, and dental oncology are amongst the most suited disciplines for virtual examination $[17,18]$. The accessibility of oral cavity to user-friendly imaging devices makes telemedicine an appealing solution for the management of OM. Furthermore, telemedicine offers reinforcement of a physician-patient relationship.

Given the popularity of mobile phone-integrated cameras, the idea of obtaining images of the oral surfaces seems feasible. However, the quality of these photos does not enable us to apply this concept universally. The dedicated devices for intra-oral imaging provide a better view, and they usually have an intra-oral video feature [19]. In particular, compared with still photos, the use of intra-oral cameras can be associated with several advantages for oral care. The COVID-19 pandemic boosted the use of intra-oral cameras to deliver remote healthcare. As this technology is expected to improve, it has great potential.

Telemedicine has shortcomings. Most notably, the examination is limited since palpation and percussion are impossible, and even with imaging technology, it may be challenging to visualize certain mucosal areas.

\section{Conclusion}

In times of emergency, treatment of cancer patients with curative intent should be kept as a priority. Therefore, supportive treatment to patients should be maintained. New models of supportive care for OM may be implemented which could represent an example of how to reshape care for toxicities.

Acknowledgments The authors would like to thank the following members of the Mucositis Study Group of MASCC/ISOO who shared their personal experience: Alan Roger Santos-Silva, DDS, PhD, Oral Diagnosis Department, University of Campinas, UNICAMP, Sao Paulo, Brazil; Vanessa Tilly, DDS, Dental Oncology Service, Instituto do Câncer do Estado de São Paulo, Faculdade de Medicina da Universidade de São Paulo, São Paulo, Brazil; Abhishek Kandwal, MDS, PGDMLS, PGDHHM, Dental Surgery Department, Supportive Care Dentistry, Cancer Research Institute, Himalayan Institute of Medical Sciences, Swami Rama Himalayan University, Dehradun, India; Wagner Gomes Silva, DDS, Dental Oncology Service, Instituto do Câncer do Estado de São Paulo, Faculdade de Medicina da Universidade de São Paulo, São Paulo, Brazil. Denise Vieira Travassos, $\mathrm{PhD}$, Faculdade de Odontologia, Universidade Federal de Minas Gerais, Belo Horizonte, Minas Gerais, Brazil.

Authors' contributions PB and SE contributed to the concept development, all the coauthors contributed to the writing of the manuscript.
Data availability The authors have full control of all the primary data and agree to allow the journal to review the data, if requested.

\section{Compliance with ethical standards}

Conflict of interest The authors declare that they have no conflict of interest.

Ethics approval Not applicable (not a clinical trial).

Consent to participate Not applicable (not a clinical trial).

Consent for publication All the coauthors approve the manuscript.

Code availability Not applicable.

\section{References}

1. Ando M, Ando Y, Hasegawa Y, Shimokata K, Minami H, Wakai K, Ohno Y, Sakai S (2001) Prognostic value of performance status assessed by patients themselves, nurses, and oncologists in advanced non-smallcell lung cancer. Br J Cancer 85:1634-1639. https://doi.org/10.1054/bjoc.2001.2162

2. Karvonen-Gutierrez CA, Ronis DL, Fowler KE, Terrell JE, Gruber SB, Duffy SA (2008) Quality of life scores predict survival among patients with head and neck cancer. J Clin Oncol 26:2754-2760. https://doi.org/10.1200/JCO.2007.12.9510

3. Marandino L, Necchi A, Aglietta M, di Maio M (2020) COVID-19 emergency and the need to speed up the adoption of electronic patient-reported outcomes in cancer clinical practice. JCO Oncol Pract 16:295-298. https://doi.org/10.1200/OP.20.00237

4. Stiff PJ, Erder H, Bensinger WI, Emmanouilides C, Gentile T, Isitt J, Lu ZJ, Spielberger R (2006) Reliability and validity of a patient self-administered daily questionnaire to assess impact of oral mucositis $(\mathrm{OM})$ on pain and daily functioning in patients undergoing autologous hematopoietic stem cell transplantation (HSCT). Bone Marrow Transplant 37:393-401

5. Sandler KA, Mitchell SA, Basch E, Raldow AC, Steinberg ML, Sharif J, Cook RR, Kupelian PA, McCloskey SA (2018) Content validity of anatomic site-specific patient-reported outcomes version of the common terminology criteria for adverse events (PROCTCAE) item sets for assessment of acute symptomatic toxicities in radiation oncology. Int J Radiat Oncol Biol Phys 102(1):44-52

6. Eggers M, Koburger-Janssen T, Eickmann M, Zorn J (2018) In vitro bactericidal and virucidal efficacy of povidone-iodine gargle/mouthwash against respiratory and oral tract pathogens. J Infect Dis Ther 7:249-259. https://doi.org/10.1007/s40121-0180200-7

7. Eggers M, Eickmann M, Zorn J (2015) Rapid and effective virucidal activity of povidone-iodine products against Middle East respiratory syndrome coronavirus (MERS-CoV) and modified vaccinia virus Ankara (MVA). J Infect Dis Ther 4:491-501

8. Kawana R, Kitamura T, Nakagomi O et al (1997) Inactivation of human viruses by povidone-iodine in comparison with other antiseptics. Dermatology 195(Suppl 2):29-35

9. Bernstein D, Schiff G, Echler G, Prince A, Feller M, Briner W (1990) In vitro virucidal effectiveness of a $0.12 \%$-chlorhexidine gluconate mouthrinse. J Dent Res 69:874-876. https://doi.org/10. $1177 / 00220345900690030901$

10. Hong CHL, Gueiros LA, Fulton JS et al (2019) Systematic review of basic oral care for the management of oral mucositis in cancer 
patients and clinical practice guidelines. Support Care Cancer 27: 3949-3967. https://doi.org/10.1007/s00520-019-04848-4

11. Al-Shamsi HO, Alhazzani W, Alhuraiji A et al (2020) A practical approach to the management of cancer patients during the novel coronavirus disease 2019 (COVID-19) pandemic: an international collaborative group. Oncologist 25:e936-e945. https://doi.org/10. 1634/theoncologist.2020-0213

12. Day AT, Sher DJ, Lee RC, Truelson JM, Myers LL, Sumer BD, Stankova L, Tillman BN, Hughes RS, Khan SA, Gordin EA (2020) Head and neck oncology during the COVID-19 pandemic: reconsidering traditional treatment paradigms in light of new surgical and other multilevel risks. Oral Oncol 105:104684. https://doi. org/10.1016/j.oraloncology.2020.104684

13. Lou E, Beg S, Bergsland E, Eng C, Khorana A, Kopetz S, Lubner S, Saltz L, Shankaran V, Zafar SY (2020) Modifying practices in GI oncology in the face of COVID-19: recommendations from expert oncologists on minimizing patient risk. JCO Oncol Pract 16:383388. https://doi.org/10.1200/OP.20.00239

14. Elad S, Cheng K, Lalla RV et al (2020) The MASCC/ISSO clinical practice guidelines for the management of mucositis secondary to cancer therapy. Cancer 2020:4423-4431. https://doi.org/10.1002/ cncr. 33100

15. Faria KM, Gomes-Silva W, Kauark-Fontes E et al (2020) Impact of pandemic COVID-19 outbreak on oral mucositis preventive and treatment protocols: new perspectives for extraoral photobiomodulation therapy. Support Care Cancer 21:1-4

16. Treister NS, London WB, Guo D, Malsch M, Verrill K, Brewer J, Margossian S, Duncan C (2016) A feasibility study evaluating extraoral photobiomodulation therapy for prevention of mucositis in pediatric hematopoietic cell transplantation. Photomed Laser Surg 34:178-184. https://doi.org/10.1089/pho.2015.4021

17. Prasad A, Brewster R, Newman JG, Rajasekaran K (2020) Optimizing your telemedicine visit during the COVID-19 pandemic: practice guidelines for patients with head and neck cancer. Head Neck 42:1317-1321. https://doi.org/10.1002/hed.26197

18. Pollock K, Setzen M, Svider PF (2020) Embracing telemedicine into your otolaryngology practice amid the COVID-19 crisis: an invited commentary. Am J Otolaryngol 41:102490. https://doi. org/10.1016/j.amjoto.2020.102490

19. Murrell M, Marchini L, Blanchette D et al (2019) Intraoral camera use in a dental school clinic: evaluations by faculty, students, and patients. J Dent Educ 83:1339-1344. https://doi.org/10.21815/JDE. 019.140

Publisher's note Springer Nature remains neutral with regard to jurisdictional claims in published maps and institutional affiliations. 